\title{
Sero-Prevalence of Human Immunodeficiency Virus (HIV-1) among High Risk Groups in Abuja, Nigeria
}

\author{
Shehu Busu Mohammed ${ }^{*}$, Yakubu Ya'aba1, Moses Chinenye Abarike1, John Baba² \\ ${ }^{1}$ Department of Microbiology and Biotechnology, National Institute for Pharmaceutical Research and Development (NIPRD), \\ Idu-Abuja, Nigeria \\ ${ }^{2}$ Department of Microbiology, Ibrahim Badamasi Babangida University, Lapai, Niger State, Nigeria \\ Email: ^mshehubusu@yahoo.com,yakyabnig@yahoo.com, abarike10@gmail.com, babajohn200133@yahoo.co.uk
}

How to cite this paper: Mohammed, S.B., Ya'aba, Y., Abarike, M.C. and Baba, J. (2019) Sero-Prevalence of Human Immunodeficiency Virus (HIV-1) among High Risk Groups in Abuja, Nigeria. Open Journal of Epidemiology, 9, 89-103. https://doi.org/10.4236/ojepi.2019.91009

Received: November 23, 2018

Accepted: February 22, 2019

Published: February 25, 2019

Copyright $\odot 2019$ by author(s) and Scientific Research Publishing Inc. This work is licensed under the Creative Commons Attribution International License (CC BY 4.0).

http://creativecommons.org/licenses/by/4.0/

\begin{abstract}
Measurement of HIV prevalence among the general population as well as among specific sub-groups who are at high risk of infection is crucial for planning and for providing health care for those who are infected. This study was aimed to determine the prevalence of HIV-1 infection among high risk groups in Abuja. The testing for the presence of HIV antibodies was carried out using Determine ${ }^{\circledast}$ HV-1/2 Test Cards (Inverness Medical, Japan), Unigold $^{\mathrm{TM}}$ kit (Trinity Biotech, Ireland) and Stat Pak ${ }^{\circledast} \mathrm{HIV}-1 / 2$ (Chembio Diagnostic Systems, Inc. USA). A total of 1587 high risk persons were screened for HIV-1, 739 (46.6\%) were males while 848 (53.4\%) were females. 261 (16.4\%) tested HIV-1 positive, out of which 74 (5.3\%) were males and 190 (11.1\%) were females. This study indicates that the incidence of HIV-1 is higher among the females. Prevalence is higher within the age range of $26-30$ years $(5.17 \%)$ and highest prevalence was observed within the age range of 31 - 35 years in males (1.32\%) and of 26 - 30 years in females (3.91\%). Commercial sex workers had the highest prevalence of HIV-1 (7.01\%), while Commercial Motorcyclists had the least $(2.02 \%)$ ( $\mathrm{p} \leq 0.05)$. This study has shown that there are local sub-epidemics of HIV infection in Abuja.
\end{abstract}

\section{Keywords}

HIV, Prevalence, Commercial Sex Workers, Algorithm, Unigold, Determine

\section{Introduction}

Human immunodeficiency virus (HIV) infection remains a global problem with approximately 36.9 million people living with HIV by the end of 2017. About 1.8 
million people became newly infected and 940,000 people died of AIDS related illness in 2017 alone [1] [2]. Gaston [3] reported that sub-Saharan Africa continues to be the most heavily affected region in the world. According to Joint United Nations Global Fact Sheet, [4], sub-Saharan Africa is hosting more than two-third of all people with HIV/AIDS globally, which means that over $66 \%$ of the people living with HIV are living in the region. It is the hardest hit region in the world followed by Asia and the Pacific. The data reported by countries globally show that HIV prevalence among high risk populations is substantially higher than in the general population. In lower prevalence settings, the majority of HIV infection occurs among key populations such as sex workers (SW), intravenous drug users (IDUs), transgenders, prisoners, gaymen, men having sex with men (MSM) and their sexual partners. In sub-Saharan Africa, key populations and their sexual partners account for $25 \%$ of new infections in 2015. Globally gaymen and MSM accounted for 12\% of new infections in 2015 alone. Commercial sex workers (CSWs) and IDUs accounted for 5\% and $8 \%$ of new infections respectively in 2015 [5]. UNAIDS, [3] reported that $9 \%$ of the people infected with HIV globally, are from Nigeria.

Monitoring and evaluation indicators for HIV program response among key populations, (sex workers, people who inject drugs, men who have sex with men, transgender people) are critical for reviewing the global response [6]. Surveillance of the HIV pandemic started in the middle of 1980s with information about key populations. Continuous surveillance of specific target group over the years allows the understanding of the trend of HIV epidemic within the stipulated regions as well as population sub-groups [7]. Although, early clinical case reports of patients with AIDS focused on clinical manifestations and immunological findings, which also noted the presence or absence of behavioral risk, including homosexuality, injecting drug use, and prostitution populations [8], was characterised by insufficient data which has been a challenge for monitoring the epidemic response among key populations [9]. At present, HIV surveillance systems in various regions of the world have some common and distinctive features. A wide use of sentinel sero-epidemiological surveillance among female clients of antenatal clinics as well as among clients of venerological clinics is typical of African countries. In economically developed countries, surveillance is still focused on the registration of AIDS cases. High risk groups (HRGs) are very important sub-groups for the spread of HIV infection as well as for control of the epidemics.

Measures addressing particularly vulnerable sections of the population such as sex workers, men who have sex with men, migrant populations such as distance travellers needed to be increased. Evidence-informed decisions about effective prevention require knowledge of local epidemics, how they are changing over time, and who is currently at greatest risk of HIV exposure. Data generated from HRGs in any locality can easily be used for trending and programming. Therefore, a study like this in Abuja a cosmopolitan, very young administrative capital city of Nigeria which is continuously receiving people of active sexual age in 
search of job is very key to enable effective control and preventive packages. The objective of this cross-sectional study was to investigate the prevalence of HIV/AIDS among selected high risk groups in Abuja the Federal Capital Territory, Nigeria.

\section{Materials and Methods}

\subsection{Study Area}

This research work was conducted in Abuja the Federal Capital Territory (FCT) from March to end of July 2018. Abuja is the developing Federal Capital City of Nigeria purposely built to replace Lagos, which hitherto had been the nation's capital and which it officially replaced in December 1991, after 15 years of planning and construction, lying between latitude $8.25^{\circ}$ and $9.20^{\circ}$ north of the equator and longitude $6.45^{\circ}$ and $7.39^{\circ}$ east of Greenwich Meridian. It is located at the centre of the country with a landmass of approximately $7315 \mathrm{~km}^{2}$, of which the actual city occupies $275.3 \mathrm{~km}^{2}$. It is situated within the Savannah region with moderate climatic conditions. The territory is located just north of the confluence of the River Niger and Benue River. It is bordered by the states of Niger to the West and North, Kaduna to the northeast, Nasarawa to the east and south, and Kogi to the southwest [10].

\subsection{Study Population}

People with high-risk behaviors and those vulnerable to high risk factors were recruited for this study. These included pregnant women attending ante-natal clinics, commercial sex workers (CSWs), patients attending sexually transmissible infection clinics and Commercial motorcyclists in Abuja. They were counseled and those that voluntarily consented were recruited for the study. Recruitment was done in the following selected hospitals and communities within Abuja: Kubwa General Hospital, Asokoro General Hospital, University of Abuja Teaching Hospital and Nyanya General Hospital for people attending antenatal clinics and those attending sexually transmissible clinics. Community based recruitment was done at Nyanya, Kado, Mabushi among commercial sex workers and Okada riders.

\subsection{Experimental Design}

Cohorts of people of high risk behaviors and those vulnerable to high risk behaviors were formed without bias to age or sex. The recruitment was therefore non-randomized and questionnaires were administered on those that consented to participate in the study. Voluntary HIV testing was conducted for the respondents.

\subsection{Sample Size}

A total of one thousand five hundred and eighty seven blood samples were collected. Seven hundred and thirty nine (739) of the populations were males while 
eight hundred and forty eight (848) were females within the age range of 11 and 65 years. 400 samples were collected from commercial sex workers, 408 from STI clinic attendees, 379 from commercial motorcyclists and 400 from pregnant women attending antenatal clinics.

\subsection{Demographic Information}

For purposes of this study, the information collected from the participants includes age, sex, Occupation and residential address through the administration of questionnaires

\subsection{Ethical Consideration}

Ethical clearance was sought from the Institutional Review Board of the National Institute for Pharmaceutical Research and Development Abuja and was endorsed by the authority of the facilities used for cohort development. Participants were given group sensitization talk and counseling before their consent was sought. Those that were willing to participate in the study were made to sign consent form and were given code numbers which appeared on the consent forms, sample container and finally in the result. They were traced back to the points of sampling at an agreed time for issuance of result if they so wished. The results were given to individuals after post counseling and those that tested negative were advised to repeat the test after three months in any nearby health facility while those that were positive were given reference letters to nearby facilities for care and support and treatment for the people living with HIV/AIDS.

\subsection{Sample Collection}

Sample collection was done by finger pricking according to the standard practice. Briefly this was done by choosing a finger and swabbing the tip of the finger using cotton wool soaked in $70 \%$ alcohol. The alcohol is allowed to dry off and a disposable lancet was used to pierce the finger deep enough to allow adequate flow of blood. Two capillary tubes were filled with blood and used for the test.

\subsection{Sample Analysis}

The protocol for the serology was according to WHO/UNAIDS strategy II HIV testing algorithm [11]. Briefly, two screening test kits were used for the test, but a non-reactive result on the first ending the testing (i.e., a negative result is reported). A positive result on the first test requires that the sample be tested by a second test.

All the One thousand five hundred and eight seven samples collected were tested for HIV-1 antibody using Uni-Gold HIV Test kit and those that were reactive with the first kits are repeated using Serocard HIV-1/2 Antibody Test kit according to manufacturer's instructions. The reactive samples were reported as positive, while the nonreactive were reported as negative. 


\subsection{Statistical Analysis}

All statistical analyses were performed using Statistical Product and Service Solution (SPSS) software (version 17.0, SPSS, Chicago, USA). The data was subjected to ANOVA to compare the groups and $(\mathrm{p} \leq 0.05)$ was set to be statistically significant.

\section{Results}

\subsection{Distribution of HIV-1 among Respondents According to Sex}

The results of the one thousand five hundred and eighty seven $(1,587)$ persons of various high risk groups screened for antibody against HIV-1 showed that seven hundred and thirty nine 739 (46.6\%) were males while eight hundred and forty eight 848 (53.4\%) were females. Generally, 261 (16.4\%) tested HIV-1 positive, and out of them, 74 (5.3\%) were males while 190 (11.1\%) were females. Analysis of this result indicates that the incidence of HIV-1 is significantly higher ( $\mathrm{p} \leq$ 0.01) among the females than the males (Figure 1).

\subsection{Distribution of HIV-1 among Different High Risk Groups in Abuja}

Commercial sex workers had the highest prevalence of HIV-1 with 124 (8.0\%) tested positive, followed by people attending sexually transmissible diseases clinics with 61 (3.84\%) people tested positive, while out of 400 women attending antenatal clinics, $43(2.7 \%)$ were positive and out of 379 commercial motorcyclist recruited and tested in this study, $32(2.02 \%)$ were tested positive $(\mathrm{p} \leq 0.01)$ (Table 1).

\subsection{Prevalence of HIV-1 among Persons Attending STI Clinics in Abuja}

The results of the 408 persons, between the ages of 11 and 65 years among

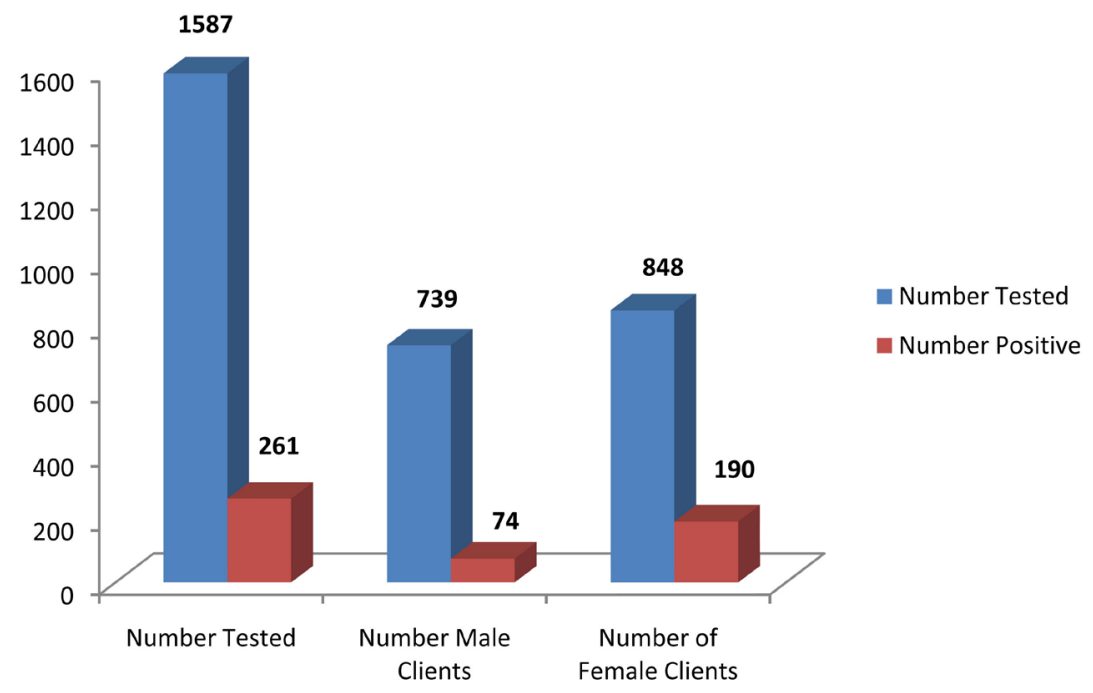

Figure 1. Prevalence of HIV among high risk groups segregatted by sex. 
Table 1. Prevalence of HIV-1 among high risk groups according to the risk factors.

\begin{tabular}{ccccccc}
\hline $\begin{array}{c}\text { High Risk } \\
\text { Groups }\end{array}$ & $\begin{array}{c}\text { No. } \\
\text { tested }\end{array}$ & $\begin{array}{c}\text { No. } \\
\text { Positive }\end{array}$ & $\begin{array}{c}\text { No. of } \\
\text { Males }\end{array}$ & $\begin{array}{c}\text { Males } \\
\text { Positive }\end{array}$ & $\begin{array}{c}\text { No. of } \\
\text { Females }\end{array}$ & $\begin{array}{c}\text { Females } \\
\text { Positive }\end{array}$ \\
\hline CSW & $400(25.2 \%)$ & $124(7.8 \%)$ & $143(9.01 \%)$ & $25(1.58 \%)$ & $257(16.2 \%)$ & $99(6.23 \%)$ \\
STI & $408(25.7 \%)$ & $61(3.84 \%)$ & $217(13.7 \%)$ & $26(1.64 \%)$ & $191(12 \%)$ & $36(2.3 \%)$ \\
ANC & $400(25.2 \%)$ & $43(2.7 \%)$ & $0(0.00 \%)$ & $0(0.00 \%)$ & $400(25.7 \%)$ & $43(2.7 \%)$ \\
CMC & $379(23.9 \%)$ & $32(2.7 \%)$ & $37(23.9 \%)$ & $32(2.7 \%)$ & $0(0.00 \%)$ & $0(0.00 \%)$ \\
\hline
\end{tabular}

people attending STI clinics in various hospitals in Abuja were sampled for this study indicated that 217 (53\%) were males while 191 (47\%) were females. Sixty one (3.8\%) tested HIV-1 positive and $26(1.6 \%)$ of them are males while 35 (2.21\%) are females. The highest prevalence was recorded among the people within the age range of 26 - 30 and 31 - 35 each with prevalence of $0.88 \%$.

Prevalence of HIV among people attending sexually transmittable infection clinics in Abuja is statistically significantly ( $\mathrm{p} \leq 0.01$ ) (Table 2 ).

\subsection{Prevalence of HIV-1 among Commercial Sex Workers in Abuja}

The result of 400 Commercial Sex Workers age range 16 and 50 years were studied, out of which $143(9.01 \%)$ are males while 257 (16.2\%) were females, indicated that $124(7.86 \%)$ were tested HIV-1 positive. Twenty five (1.58\%) of the positive cases were males and 99 (6.24\%) were females. Analysis of this result indicate that again the prevalence of HIV-1 is significantly high $(\mathrm{p} \leq 0.01)$ among the females than the males (Table 3 ).

\subsection{Prevalence of HIV-1 among Motorcycle Taxi Drivers in Abuja}

Figure 2 shows the result of the three hundred and seventy nine men who rides commercial motorcycles in various part of Abuja, age range 16 and 50 years screened for the presence of HIV-1 antibody. It was found out that $32(2.02 \%)$ were HIV-1 antibody positive. Analysis of this result indicates that prevalence of HIV-1 is significant $(\mathrm{p} \leq 0.01)$ among this group. They were segregated according to their age and those within the age range of 26 - 30 had the highest prevalence of HIV-1 of $0.63 \%$. Transport is considered a "high-risk" occupation.

\subsection{Prevalence of HIV-1 among Pregnant Women Attending ANC in Abuja}

Table 4 shows the prevalence of HIV among four hundred pregnant women attending antenatal clinics in Abuja, age range 16 and 40 years mean age 28 years were tested for the presence of HIV-1 antibody and the result showed that $43(2.7 \%)$ tested positive. They were segregated according to their age group and women within the age range of 26 - 30 years had the highest prevalence of HIV-1 in the group with 17 (1.07\%) tested positive. Analysis of this result indicates that the prevalence of HIV-1 is significant $(p \leq 0.01)$ among the groups. 
Table 2. Prevalence of HIV-1 among persons attending STI clinics in Abuja according to their sexes disaggregated by age brackets.

\begin{tabular}{ccccc}
\hline \multirow{2}{*}{ Age Bracket } & \multicolumn{2}{c}{ Male } & \multicolumn{2}{c}{ Females } \\
\cline { 2 - 5 } & $\mathrm{N}$ & $\mathrm{P}$ & $\mathrm{N}$ & $\mathrm{P}$ \\
\hline $11-15$ & $0(0.00 \%)$ & $0(0.00 \%)$ & $2(0.13 \%)$ & $2(0.13 \%)$ \\
$16-20$ & $11(0.69)$ & $0(0.00 \%)$ & $18(1.13 \%)$ & $2(0.13 \%)$ \\
$21-25$ & $45(2.84)$ & $2(0.13 \%)$ & $47(2.96 \%)$ & $9(0.57 \%)$ \\
$26-30$ & $47(2.96)$ & $4(0.25 \%)$ & $57(3.59 \%)$ & $10(0.63 \%)$ \\
$31-35$ & $44(2.77 \%)$ & $6(0.38 \%)$ & $25(1.58 \%)$ & $8(0.5 \%)$ \\
$36-40$ & $25(1.58 \%)$ & $8(0.5 \%)$ & $21(1.32 \%)$ & $4(0.25 \%)$ \\
$41-45$ & $16(1.01 \%)$ & $3(0.19 \%)$ & $6(0.38 \%)$ & $2(0.13 \%)$ \\
$46-50$ & $12(0.76 \%)$ & $2(0.13 \%)$ & $6(0.38 \%)$ & $0(0.00 \%)$ \\
$51-55$ & $8(0.5 \%)$ & $1(0.06 \%)$ & $7(0.44 \%)$ & $0(0.00 \%)$ \\
$56-60$ & $7(0.44 \%)$ & $0(0.00 \%)$ & $2(0.13 \%)$ & $0(0.00 \%)$ \\
$61-65$ & $2(0.13 \%)$ & $0(0.00 \%)$ & $0(0.00 \%)$ & $0(0.00 \%)$ \\
\hline
\end{tabular}

Footnote: $\mathrm{N}=$ Number of clients, $\mathrm{P}=$ Number of positive clients.

Table 3. Prevalence of HIV-1 among commercial sex workers in Abuja according to sex disaggregated by age bracket.

\begin{tabular}{ccccc}
\hline \multirow{2}{*}{ Age bracket } & \multicolumn{2}{c}{ Male } & \multicolumn{2}{c}{ Female } \\
\cline { 2 - 5 } & $\mathrm{N}$ & $\mathrm{P}$ & $\mathrm{N}$ & $\mathrm{P}$ \\
\hline $11-15$ & $0(0.00 \%)$ & $0(0.00 \%)$ & $0(0.00 \%)$ & $0(0.00 \%)$ \\
$16-20$ & $9(0.57 \%)$ & $1(0.06 \%)$ & $38(2.39 \%)$ & $8(0.5 \%)$ \\
$21-25$ & $27(1.7 \%)$ & $1(0.06 \%)$ & $66(4.16 \%)$ & $24(1.51 \%)$ \\
$26-30$ & $33(2.07 \%)$ & $6(0.37 \%)$ & $69(4.33 \%)$ & $35(2.21 \%)$ \\
$31-35$ & $27(1.7 \%)$ & $9(0.57 \%)$ & $48(3.02 \%)$ & $17(1.07 \%)$ \\
$36-40$ & $17(1.07 \%)$ & $4(0.25 \%)$ & $20(1.26 \%)$ & $9(0.57 \%)$ \\
$41-45$ & $16(1.01 \%)$ & $4(0.25 \%)$ & $9(0.57 \%)$ & $5(0.32 \%)$ \\
$46-50$ & $14(0.88 \%)$ & $0(0.00 \%)$ & $7(0.44 \%)$ & $1(0.06 \%)$ \\
$51-55$ & $0(0.00 \%)$ & $0(0.00 \%)$ & $0(0.00 \%)$ & $0(0.00 \%)$ \\
$56-60$ & $0(0.00 \%)$ & $0(0.00 \%)$ & $0(0.00 \%)$ & $0(0.00 \%)$ \\
$61-65$ & $0(0.00 \%)$ & $0(0.00 \%)$ & $0(0.00 \%)$ & $0(0.00 \%)$ \\
\hline
\end{tabular}

Footnote: $\mathrm{N}=$ Number of clients, $\mathrm{P}=$ Number of positive clients.

Table 4. Prevalence of HIV-1 among Antenatal clinic attendees in Abuja segregated by their age group.

\begin{tabular}{ccc}
\hline Age Bracket & \multicolumn{2}{c}{ ANC } \\
\cline { 2 - 3 } & $\mathrm{N}$ & $\mathrm{P}$ \\
\hline $16-20$ & $29(1.82 \%)$ & $4(0.25 \%)$ \\
$21-25$ & $113(7.12 \%)$ & $1(0.06 \%)$ \\
$26-30$ & $146(9.19 \%)$ & $17(1.07 \%)$ \\
$31-35$ & $83(5.22 \%)$ & $15(0.94 \%)$ \\
$36-40$ & $29(1.82 \%)$ & $6(0.37 \%)$ \\
Total & 400 & $43(2.7 \%)$ \\
\hline
\end{tabular}




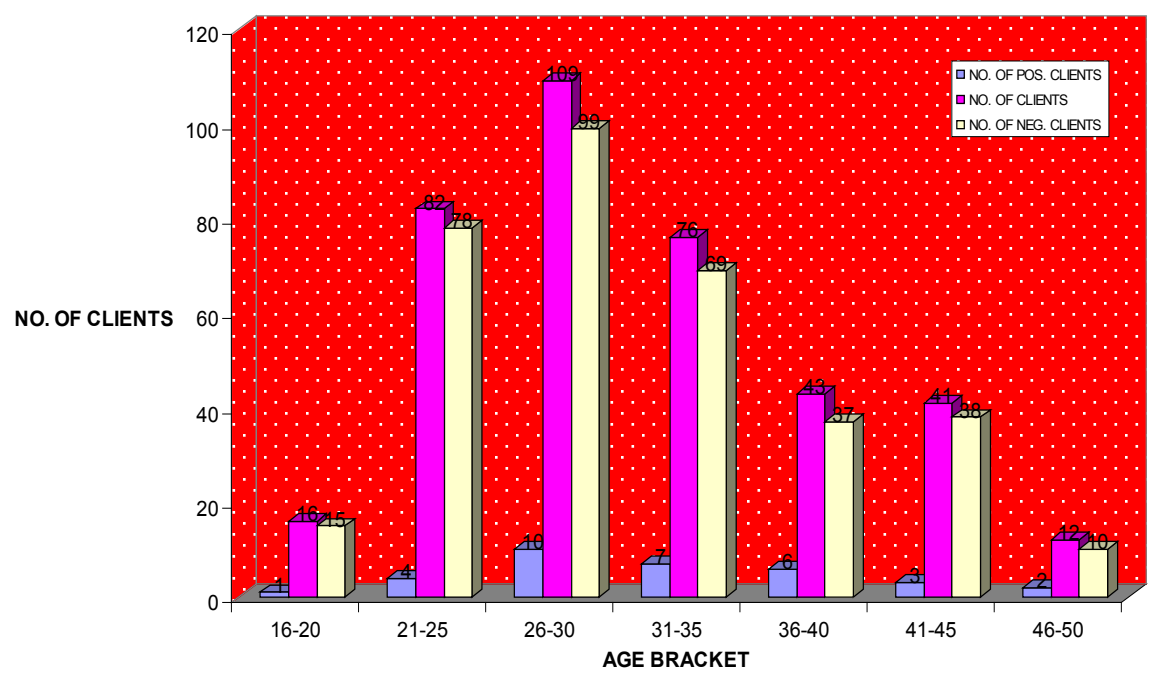

Figure 2. Prevalence of HIV-1 among commercial Motorcyclists in Abuja disaggregated by age group.

\section{Discussion}

High risk groups (HRGs) are very important sub-groups for the spread of HIV infection as well as for control of the epidemics. In this study the role of high-risk behavior in vulnerability to HIV infection was explored. There was a varied prevalence of HIV among different sub-groups depending on the type of risk behavior and level of vulnerability from such behavior. The result showed positive association, between high risk behaviors and prevalence of HIV.

The analysis of the result showed, 261 (16.4\%) people tested HIV-1 positive which is similar to the previous study by [12], where $15.5 \%$ of people aged between 10 - 50 years were found to be positive among people tested for HIV at the diagnostic laboratory of National Hospital Abuja. However, the result of this study is relatively high compare to the national sentinel surveillance rate of $4.1 \%$ of 2014. This is mainly because sero-epidemiological surveillance among female clients of antenatal clinics is the main source of national HIV prevalence. In economically developed countries, surveillance is focused on the registration of AIDS cases. The result indicated that more females were infected with HIV than males which is an indication that heterosexual contact of transmission is the major route of transmission fuelling the epidemics in Nigeria [13] and also in agreement with the observation that women constitute more than half of all people living with HIV, and in sub-Sahara Africa, women constitute $58 \%$ of all people living with HIV [4]. It showed the same trend with the general population survey in 2007 which put the prevalence among the females at $4 \%$ and $3.2 \%$ among the males [14].

On disaggregation according to the age brackets, the men within the age bracket of 31 - 35 years has the highest prevalence while female within the age bracket of $26-30$ years has the highest prevalence. This is also comparable to the report by [15] where the highest prevalence among the female sex workers were among the age of 25 - 29 years. 
The risk group with the highest prevalence according to this study were commercial sex workers and then the people attending STI clinics, pregnant women attending antenatal clinics and the least was commercial motorcycle riders. The number of males attending STI clinics that participated in this study was higher than the number of female respondents. This is however contrary to the finding of a study by [16] where the number of females attending STI Clinics was higher than the number of males. The study also finds out that both males and females within the economically active age (21 - 35 years) are more which is in agreement with the findings of [17] where people within the age of $25-44$ were mostly the clients of STI Clinics in India. Prevalence of HIV among STI clients in this study, was higher among the female clients compare to the male clients. The prevalence of HIV among STI clinic attendees in this study is much lower than the findings of $44.4 \%$ among Malawians, 33\% among Ethiopians, $14.1 \%$ among Tanzanians 57\% among Ugandans [3] and 26.6\% among FSWs attending STI clinics in Cote d'Ivoire [18].

Globally, HIV infection remains a significant issue for key populations such as men who have sex with men (MSM) and female sex workers. It is believed to be one of the risky sexual practices in the spread of HIV both from a sex worker to a male customer and from husband to the wife or vice versa [19]. A meta-analysis of FSW studies in low to middle-income countries indicated that FSW in sub-Saharan Africa had 12.4 times the odds of HIV compared with all women of reproductive age. The HIV prevalence among commercial sex workers in this study was $7.56 \%$ in this study which is an indication that the epidemics is in its concentrated stage and this group of people serve as a major source of transmission of HIV. The female sex workers were found to have about four times the prevalence among the male sex workers. The prevalence of HIV among commercial sex workers is less than the result of $10.6 \%$ by [17], $22.5 \%$ by [20], $34.4 \%$ by [21] and $31 \%$ by [22], but lower than $3.8 \%$ by [23]. The study revealed that more female sex workers are infected with HIV than the male counterparts. This is in comparison to the findings of [24] of $2.74 \%$ among FSW and $2.67 \%$ among MSW, $6.24 \%$ among females and $1.58 \%$ among males by [22]. The study indicated that $1.58 \%$ prevalence of HIV among MSW is lower than the findings of $5.3 \%$ from China [25] and 6.25 by [22], but comparable to $1.4 \%$ among MSWs in Northern Mexico [23]. HIV prevalence in FSW varies within and across west African countries, the findings of this study showed a lower prevalence compare to $20 \%$ by [26] $24.75 \%$ by [22]. According to meta-analysis of HIV among FSW in west Africa, prevalence of HIV among FSWs was 20.1\% in Senegal, 25.7\% in Bobo-Dioulasso, Burkina Faso, 26.6\% in Côte d'Ivoire, $30.4 \%$ in Cotonou, Benin, $45.4 \%$ in Lome, Togo and up to $68.6 \%$ in a study in Ghana and Benin [3].

Motor bike is a major source of transport services in most Nigerian towns and cities. As commercial transporters, they exhibit the same lifestyle with taxi drivers and hence vulnerable to high risk behaviours. The findings of this study indicated that HIV is endemic among this population in Abuja, Federal Capital 
Territory. The result of this study is however, lower than 5.7\% obtained among mobile workers including drivers in Ethiopia [27], 7.5\% among motorcycle taxi drivers in Kampala Uganda [28] and 37\% among bus, taxi and tricycle drivers in Awka Nigeria [29]. Though it is a general trend that the prevalence among MSMs is times higher odd of infection risk than the commercial motorcycle taxi drivers, which means that the commercial motorcycle taxi drivers experience a lower risk compare to MSMs. The results of this study showed that the prevalence of HIV is higher among this group compare to MSWs. This can be explained by the fact that both MSM and FSW are population that are defined based on their high risk behaviour while commercial motorcycle taxi drivers are people with a specific occupation that may exhibit different sexual behavior [30].

The HIV prevalence among pregnant women attending antenatal clinics are used as the national HIV prevalence data in developing world including Nigeria. The result of this study among pregnant women is comparable to latest Nigeria national prevalence figure of $3.0 \%$ of 2014 . Though it is far below the trend analysis of state HIV prevalence rate of 5.8\% in Abuja Federal Capital Territory [31] and the result of 7.9 from National Hospital Abuja [32] but higher than $1.5 \%$ reported by [33] in four states in Southern India. [23] reported prevalence of $0.6 \%$ among non-commercial partners in Northern Mexico. According to 2010 sentinel survey in Nigeria, the prevalence among the general population was lower than among pregnant women and most at-risk populations (MARPs) [15]. But in contrary, this study recorded higher prevalence among high risk population than the general population.

\section{Conclusion}

Nigeria is a country in a concentrated phase of HIV epidemics despite declining prevalence. The mode of transmission of HIV in Nigeria is mostly by heterosexual means thereby concentrating the epidemic around the heterosexuals. The high-risk groups are of great concern especially in Abuja considering the result of this study. This calls for an enhanced surveillance system targeting most-at-risk populations. Intensive campaigns on risk reduction, infection control measures, sexual and health reproductive services and gender equality should be enhanced. Methods to increase uptake of HIV testing should be put in place to effectively mitigate transmission. Finally, treatment, quality care and support for infected persons should be readily available and accessible at the primary health care level.

\section{Limitation of the Study}

There was no enough fund to widened the scope to taxi drivers and long journey travelers since the research was solely funded by personal contributions. Only very few populations of the male sex workers contacted were ready to participate because of fear of stigmatization and arrest by government security agencies inspite all assurances of not linking the result of the research to any individual. 


\section{Acknowledgements}

We sincerely acknowledge University of Abuja, Abuja and Director General/Chief Executive Officer and management of National Institute for Pharmaceutical Research and Development Abuja for their support. We also acknowledge the members of the Institutional Review Board of National Institute for Pharmaceutical Research and Development Abuja for granting us the ethical approval for the study.

\section{Conflicts of Interest}

The authors declared no conflict of interest.

\section{References}

[1] WHO Factsheet (2018) Global HIV/AIDS Statistics 2018. http://www.unaids.org/en/resources/factsheet

[2] Onoja, A., Mohammed, S.B., Ya'aba, Y., Liman, M. and Njab, J. (2016) Seroprevalence of HIV among the People of Lake Chad Basin of Borno State, Nigeria. JOPAT, 15, 31-39.

[3] Gaston, D., Silas, Q. and Patrick, S.S. (2014) HIV Epidemic among Key Populations in West Africa. Current Opinions on HIV AIDS, 9, 506-513. https://doi.org/10.1097/COH.0000000000000090

[4] Joint United Nations Global Factsheet (2015) The Global HIV/AIDS Epidemics. http://www.unaids.org/sites/default/files/media.asset/factsheet_2015_en_pdf

[5] UNAIDS (2017) State of the AIDS Epidemic. http://www.unaids.org/en/resources/document/2017/2017_data

[6] UNAIDS (2014) The Beginning of the End of the AIDS Epidemics. UNAIDS Gap Report. http://www.aidsdatahub.org

[7] Gall, J., Sabin, K., Frescura, L., Sabin, M.L., Eekkola, T. and Toskin, I. (2017) Global Trends of Monitoring and Data Collection on the HIV Response among Key Populations since the $2001 \mathrm{UN}$ Declaration of Commitment on HIV/AIDS. AID, 2, 34-43.

[8] De-Coul, E.L., Warning, T.D., Koediik, F.D. and Dutch STI Clinics (2014) Sexual Behaviour and Sexually Transmitted Infections in Sexually Transmitted Infection Clinic Attendees in the Netherlands, 2007-2011. International Journal of STD and AIDS, 25, 40-51. https://doi.org/10.1177/0956462413491736

[9] Weir, S.S., Baral, S.D., Edwards, J.K., Zadrozny, S., Hargreaves, J., Zhao, J. and Sabin, K. 2018) Opportunities for Enhanced Strategic Use of Surveys, Medical Records, and Program Data for HIV Surveillance of Key Populations: Scoping Review. JMIR Public Health and Surveillance, 4, e28. https://doi.org/10.2196/publichealth.8042

[10] Henry (2008) The Free Online Encyclopaedia. 5th Edition, New York.

[11] Constantine, N.T., Rebecca, D.S. and Elizabeth, M.D. (2005) Epidemiology. In: Retroviral Testing and Quality Assurance: Essentials for Laboratory Diagnosis. MedMira Laboratories Inc., 155 Chain Lake Drive Canada, 46-49.

[12] Muhammad, T., Ene, A.C., Atanda, G.O., Nwankwo, E.A. and Baba, M.M. (2009) Seroprevalence of HIV Infection Among Patients Attending Sexually Transmitted Diseases (STDs) Clinic at National Hospital Abuja, Nigeria. Scientific Research Es- 
say, 4, 065-068.

[13] NACA (2014) Annual Report. http://naca.gov.ng/naca-annual-report-2014

[14] Adeniyi, F.F., Samson, B.A. and Erhabor, I. (2016) Marital Status and HIV Prevalence among Women in Nigeria: Ingredients for Evidence Based Programing. International Journal of Infectious Diseases, 48, 57-63.

[15] FMOH (2007) HIV Integrated Biological and Behavioural Surveillance Survey 2006. Federal Ministry of Health, Abuja, Nigeria. http://www.popcouncil.org/pdfs/2006/IBBSS2007.pdf

[16] Dilip, K., Swati, D. and Ratnendra, S. (2017) Status of Syndromic Management of Clients and Their Partners at STI Clinic in a Suburban Area of Mumbai, India. International Journal of Medical Research \& Health Sciences, 6, 115-120.

[17] Getu, K. and Tadesse, A. (2013) Prevalence and Determinants of HIV among Symptomatic STI Cases in Southern Nations, Nationalities and People's Regional States, Ethiopia. Universal Journal of Public Health, 1, 115-123.

[18] Vuylsteke, B., Semde, G., Sika, L., Crucitti, T., Ettiegne, T.V. and Anne, B. (2012) HIV and STI Prevalence among Female Sex Workers in Cote d'Ivoire: Why Targeted Prevention Programs Should Be Continued and Strengthened. PLoS ONE, 7, e32627.

[19] Orisatoki, R.O. and Oguntibeju, O.O. (2010) Paper HIV-Related Knowledge and Condom Use by Taxi Drivers in Southern St. Lucia, West Indies. Scientific Research and Essays, 5, 304-308.

[20] Monica, H.S., Rachel, C., Laura, F.S., Rogers, K. and Janet, S. (2016) Prevalence of HIV and Associated Risks of Sex Work among Youth in the Slums of Kampala. AIDS Research and Treatment, 2016, Article ID: 5360180. https://doi.org/10.1155/2016/5360180

[21] Degboe, B., Atadokpede, F., Adégbidi, H., Nguenmegne N.A., Geraldo, N., et al. (2017) Sexually Transmitted Infections among Sex Workers and Their Clients in Cotonou (Benin) in 2015: Prevalence and Risk Factors. Clinical Dermatology Research Journal, $2,1$.

[22] Mohammed, S.B., Onoja, A.J., Ya'aba, Y. and Abubakar, A. (2018) Sero-Prevalence of HIV-1 among Commercial Sex Workers in Abuja, Federal Capital Territory, Nigeria. Nigeria Journal of Pure \& Applied Science, 31, 3129-3136.

[23] Bazzi, A.R., Rangel, G., Martinez, G., Monica, D.U., Jennifer L.S. Bazzi, S.A., et al. (2015) Incidence and Predictors of HIV and Sexually Transmitted Infections Among Female Sex Workers and Their Intimate Male Partners in Northern Mexico: A Longitudinal, Multilevel Study. American Journal of Epidemiology, 181, 723-731. https://doi.org/10.1093/aje/kwu340

[24] Jing, Z., Rui, Y. and Dan, H. (2017) HIV Prevalence and Correlated Factors of Female Sex Workers and Male Clients in a Border Region of Yunnan Province, China. International Journal of STD \& AIDS, 1-8.

[25] Cai, W.D., et al. (2010) HIV Prevalence and Related Risk Factors among Male Sex Workers in Shenzhen, China: Results from a Time-Location Sampling Survey. Sexually Transmitted Infection, 86, 15-20. https://doi.org/10.1136/sti.2009.037440

[26] George, I., Eluwa, S.A., Strathdee, S.B., Adebajo, B., Ahonsi, A.A. and Anyanti, J. (2012) Sexual Risk Behaviors and HIV among Female Sex Workers in Nigeria. Journal of Acquired Immune Deficiency Syndromes, 61, 507-514.

[27] Lakew, Y., Benedict, S. and Haile, D. (2015) Social Determinants of HIV Infection, Hotspot Areas and Subpopulation Groups in Ethiopia: Evidence from the National 
Demographic and Health Survey in 2011. BMJ Open, 5, e008669.

[28] Lindan, C.P., Anglemyer, A., Hladik, W., Barker, J., Lubwama, G. and Rutherford, G. (2015) High-Risk Motorcycle Taxi Drivers in the HIV/AIDS Era: A Respondent-Driven Sampling Survey in Kampala, Uganda. International Journal of STD \& AIDS, 26, 336-345. https://doi.org/10.1177/0956462414538006

[29] Effiony, E.B., Umeh, S.O., Adamu, G.M. and Mbanisi, B.O. (2017) Survey of Trend of HIV/AIDS Epidemic in Awka Metropolis, Nigeria. Global Journal of Research and Reviews, 4, 25.

[30] Zhang, X., et al. (2013) Prevalence of HIV and Syphilis Infection among Long Distance Truck Drivers in China: A Data Synthesis and Meta-Analysis. International Journal of Infectious Diseases, 17, e2-e7. https://doi.org/10.1016/j.ijid.2012.07.018

[31] NACA 2015 Global AIDS Response: Country Progress Report, Nigeria GARPR 2015. Nigeria_GARPR_2015.info@naca.gov.ng.

[32] Adedamola, A.O. (2018) Seroprevalence of Human Immunodeficiency Virus, Hepatitis B, Hepatitis C, Syphilis and Co-Infections among Antenatal Women: A Retrospective Case Study at National Hospital Abuja, Federal Capital Territory (FCT), Nigeria. Texila International Journal of Public Health, 6, 19-15.

[33] Thamattoor, U., Thomas, T., Banandur, P.S.R., Duchesne, T., Abdous, B., Washington, R., et al. (2015) Multilevel Analysis of the Predictors of HIV Prevalence among Pregnant Women Enrolled in Annual HIV Sentinel Surveillance in Four States in Southern India. PLoS ONE, 10, e0131629. 


\section{Appendix}

\section{Informed Consent Demographic Information Form}

\section{1) Preamble}

Human Immunodeficiency Virus (HIV) is a global pandemic that have live with us for three decades now. This virus has broken the fabrics of our society and has spare no nation race, tribe or profession. However, the there are several factors that including behaviours that predisposes one to infection by this virus. The world has also marched the epidemics with programs that will help in controlling and preventing the spreading of HIV infection. One of it is the epidemiological survey which is key to programming.

The high-risk populations are important in the spread of HIV infection and must be incorporated into the program for effective mitigation of the spread. There is therefore need for continuous surveillance study to determine the trend of the epidemics among general and specific sub-populations.

The objective of the study is to determine the prevalence of HIV among some high risk populations in Abuja.

The study will be VERY CONFIDENTIAL, the consent forms, the samples taken and the results are coded and therefore cannot be linked to any individual. The disclosure of the result will be done with confidentiality.

If you are tested HIV positive you will be referred to a nearby health facility or anyone of your choice for treatment and care.

Remember that HIV treatment and Care is FREE in Nigeria

The importance and benefit of this study has been well explained to me and wish to/not to participate in the study.

Please tick as appropriate

Signature:

Date:-

\section{2) Please fill the appropriate box correctly}

Initial Box

1. Age in Years

2. Sex: $M$

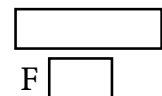

3. Occupation:

House wife

Female Commercial Sex worker

Commercial Partners of Female Sex Worker

Noncommercial Partner of Female Sex Worker

ANC

STI Clinic Attendee

Commercial Motorcycle Rider

3) Residential Address in case of need to follow up 
Thank you as you participate in this study Name of Researcher--

Sign-

Date- 